\title{
Clinical use of dexmedetomidine in monitored anesthesia care
}

\author{
Soo Kyung Lee \\ Department of Anesthesiology and Pain Medicine, Hallym University College of Medicine, Anyang, Korea
}

Monitored anesthesia care (MAC) is useful for various clinical fields such as minimally invasive surgery, gastrointestinal endoscopy, and interventional or radiological procedures. It provides suitable intraoperative conditions as well as comfort for patients. The commonly used drugs are midazolam, propofol, and opioids such as fentanyl, alfentanil or remifentanil. Occasionally, the administration of sedatives or hypnotics in conjunction with analgesics can cause significant respiratory depression and/or transient upper airway obstruction.

Dexmedetomidine is a highly selevtive $\alpha 2$-adrenoceptor agonist with eight times higher specificity for the receptor compared to clonidine. It provides excellent sedation and analgesia with minimal respiratory depression [1]. Recent multicenter trial indicated that it was an effective baseline sedative for patients undergoing a broad range of surgical procedures under MAC, providing greater patient satisfaction, less opioid requirements, and less respiratory depression compared with the placebo [2]. In patients undergoing diagnostic transesophageal echocardiography, the sedative effect of dexmedetomidine proved to be equivalent to that of the standard therapy using midazolam and fentanyl without increasing the incidences of respiratory depression or oxygen desaturation. It also seemed to be better in terms of hemodynamic results [3]. Dexmedetomidine with fentanyl could be used safely and effectively for sedation and analgesia during extracorporeal shockwave lithotripsy [4].

In the current issue of the Korean Journal of Anesthesiology [5], the authors demonstrated dexmedetomidine was a useful sedative drug for MAC in outpatients undergoing cataract surgery, and in aspects of patients' satisfaction and cardiovascular stability, it was superior to the combination of propofol and alfentanil.

However, Muller et al. [6] have showed dexmedetomidine alone was not as effective as propofol with fentanyl for providing conscious sedation during ERCP. Furthermore, it was associated with greater hemodynamic instability and longer recovery time. Spontaneously breathing pediatrics patients undergoing cardiac catheterization with dexmedetomidine and ketamine experienced insufficient sedation and analgesia and prolonged recovery compared to propofol and ketamine [7].

Dexmedetomidine leads to dose-dependent decreases in blood pressure, heart rate, and plasma catecholamine concentrations $[8,9]$. Higher concentrations of this drug can also result in systemic and pulmonary hypertension [10]. Severe bradycardia progressing to pulseless electrical activity caused by dexmedetomidine was reported in a 74-year-old man who experienced a postoperative myocardial infarction [11]. These adverse effects on cardiovascular system might limit the use of high concentrations of dexmedetomidine, and clinicians must always be careful when using this drug, especially in patients with significant cardiac disease.

Rapid administration of dexmedetomidine can lead to transient hypertension, bradycardia, or tachycardia, and therefore, administration of a loading dose for over 10 minutes is recommended [12]. The drug is sometimes used without a loading dose [11]. The report, published in the current issue of the Korean Journal of Anesthesiology [5], suggested continuous infusion of dexmedetomidine adjusted depending on the sedation scale without a loading dose neither disturbing cardiovascular stability nor delaying discharge.

It is necessary to monitor blood pressure even after discontinuation of dexmedetomidine as its infusion for 2 minutes has

Corresponding author: Soo Kyung Lee, M.D., Department of Anesthesiology and Pain Medicine, Hallym University Sacred Heart Hospital, 896, Pyeongchon-dong, Dongan-gu, Anyang 431-070, Korea. Tel: 82-31-380-3945, Fax: 82-31-385-3244, E-mail: agnetask@yahoo.co.kr (c) This is an open-access article distributed under the terms of the Creative Commons Attribution Non-Commercial License (http:// creativecommons.org/licenses/by-nc/3.0/), which permits unrestricted non-commercial use, distribution, and reproduction in any medium, provided the original work is properly cited. 
induced a long-lasting decrease in mean arterial blood pressure in the healthy volunteers, with a maximum decrease of $14 \%$ for $0.25 \mu \mathrm{g} / \mathrm{kg}$ and $16 \%$ for $0.5 \mu \mathrm{g} / \mathrm{kg}$ at 60 minutes after the discontinuance of the drug [13].

Although dexmedetomidine is an attractive drug for MAC, further studies on appropriate dosage according to patients' age or race or the presence of other drugs and on the method of infusion suitable for each procedures are required for safe use. The use of dexmedetomidine in pediatric patients is not yet approved in Korea.

\section{References}

1. Bhana N, Goa KL, McClellan KJ. Dexmedetomidine. Drugs 2000; 59: $263-8$.

2. Candiotti KA, Bergese SD, Bokesch PM, Feldman MA, Wisemandle W, Bekker AY, et al. Monitored anesthesia care with dexmedetomidine: a prospective, randomized, double-blind, multicenter trial. Anesth Analg 2010; 110: 47-56.

3. Cooper L, Candiotti K, Gallagher C, Grenier E, Arheart KL, Barron ME. A randomized, controlled trial on dexmedetomidine for providing adequate sedation and hemodynamic control for awake, diagnostic transesophageal echocardiography. J Cardiothorac Vasc Anesth 2011; 25: 233-7.

4. Kaygusuz K, Gokce G, Gursoy S, Ayan S, Mimaroglu C, Gultekin Y. A comparison of sedation with dexmedetomidine or propofol during shockwave lithotripsy: a randomized controlled trial. Anesth Analg 2008; 106: 114-9.
5. Na HS, Song IA, Park HS, Hwang JW, Do SH, Kim CS. Dexmedetomidine is effective for monitored anesthesia care in outpatients undergoing cataract surgery. Korean J Anesthesiol 2011; 61: 453-9.

6. Muller S, Borowics SM, Fortis EA, Stefani LC, Soares G, Maguilnik I, et al. Clinical efficacy of dexmedetomidine alone is less than propofol for conscious sedation during ERCP. Gastrointest Endosc 2008; 67: 651-9.

7. Tosun Z, Akin A, Guler G, Esmaoglu A, Boyaci A. Dexmedetomidine-ketamine and propofol-ketamine combinations for anesthesia in spontaneously breathing pediatrics undergoing cardiac catheterization. J Cardiothorac Vasc Anesth 2006; 20: 515-9.

8. Kallio A, Scheinin M, Koulu M, Ponkilainen R, Ruskoaho H, Viinamäki $\mathrm{O}$, et al. Effects of dexmedetomidine, a selective alpha 2-adrenoceptor agonist, on hemodynamic control mechanisms. Clin Pharmacol Ther 1989; 46: 33-42.

9. Bloor BC, Ward DS, Belleville JP, Maze M. Effects of intravenous dexmedetomidine in humans. II. Hemodynamic changes. Anesthesiology 1992; 77: 1134-42.

10. Ebert TJ, Hall JE, Barney JA, Uhrich TD, Colinco MD. The effects of increasing plasma concentrations of dexmedetomidine in humans. Anesthesiology 2000; 93: 382-94.

11. Gerlach AT, Murphy CV. Dexmedetomidine-associated bradycardia progression to pulseless electrical activity: case report and review of the literature. Pharmacotherapy 2009; 29: 1492.

12. Grant SA, Breslin DS, MacLeod DB, Gleason D, Martin G. Dexmedetomidine infusion for sedation during fiberoptic intubation: a report of three cases. J Clin Anesth 2004; 16: 124-6.

13. Bloor BC, Ward DS, Belleville JP, Maze M. Effects of intravenous dexmedetomidine in humans. II. Hemodynamic changes. Anesthesiology 1992; 77: 1134-42. 